\title{
MELHORIA DO RENDIMENTO E DO PROCESSO DE OBTENÇÃO DA BEBIDA ALCOÓlICA DE PUPUNHA (Bactris gasipaes Kunth) ${ }^{1}$
}

\author{
Jerusa S. ANDRADE ${ }^{2, *}$, Lílian PANTOJA ${ }^{2}$, Roberto N. MAEDA ${ }^{2}$
}

\begin{abstract}
RESUMO
Com frutos de pupunha (Bactris gasipaes Kunth) e fermentação natural, indios na Amazônia produzem uma bebida alcoólica turva, densa, com resíduos de polpa, denominada de "caiçuma". Pesquisas realizadas no Instituto Nacional de Pesquisas da Amazônia mostram que com hidrólise enzimática do amido, fermentação por Saccharomyces cerevisiae e filtração adequada, a limpidez e características desejáveis podem ser obtidas. Este experimento teve por objetivo aumentar o rendimento em bebida e facilitar o processo pelo aumento da proporção água:polpa no mosto e exclusão da hidrólise enzimática do amido, respectivamente. A composição química da polpa dos frutos in natura e cozidos foi determinada, e com a polpa cozida e autoclavada foi preparado o mosto completando-se a quantidade de substrato com a adição de xarope de sacarose. Após a inoculação com Saccharomyces cerevisiae a fermentação foi monitorada diariamente por sete dias através de análises químicas. A bebida foi caracterizada quanto à composição química, edulcorada e analisada sensorialmente. A cocção e autoclavagem ocasionaram hidrólise parcial do amido presente na polpa. A evolução da fermentação foi mostrada pelo consumo de açúcares e produção de ácidos e álcool. O rendimento em bebida ( \pm 60\%), graduação alcoólica de 12,1\% (v/v), atraente coloração alaranjada clara, limpidez, sabor e aroma agradáveis e boa aceitabilidade (81,90\%), mostraram a viabilidade técnica do processo na utilização da pupunha para produção de bebida. O aumento da proporção água:polpa no mosto contribuiu para o rendimento. A exclusão da hidrólise enzimática e o aumento do rendimento em bebida não interferiram na graduação alcoólica, coloração, sabor, aroma e aceitabilidade da bebida alcoólica fermentada de pupunha.

Palavras-chave: pupunha; fermentação; Saccharomyces cerevisiae; bebida alcoólica; composição quimica; análise sensorial.
\end{abstract}

\section{SUMMARY}

IMPROVEMENT ON BEVERAGE VOLUME YIELD AND ON PROCESS OF ALCOHOLIC BEVERAGE PRODUCTION FROM PEJIBAYE (BACtriS gasipaes Kunth). Pejibaye (Bactris gasipaes Kunth) fruits and natural fermentation are used by Amazonian natives to produce a thick drink called "caiçuma". The beverage presents high turbidity because of numerous pulp fragments of various sizes. A study done at the National Institute of Amazon Research showed that enzymatic starch hydrolysis, fermentation by Saccharomyces cerevisiae and filtration transformed "caiçuma" into a highly acceptable drink. The experiment was carried out with the aim of increasing beverage volume yield and process efficiency by increasing the water:pulp ratio of the mash and eliminating the starch enzymatic hydrolysis, respectively. Raw and cooked pejibaye fruits were characterized in terms of their chemical properties. The mash was prepared with pejibaye pulp (previously cooked and autoclaved) and sucrose syrup. After Saccharomyces cerevisiae inoculation, the fermentation process was monitored (every 24 hours) during seven days by physical-chemical analysis. The beverage obtained was analyzed chemically, and, after sweetening, was submitted to a sensory evaluation panel. The cooked and autoclaved fruits presented partially hydrolyzed starch. Fermentation evolution was followed by sugar consumption, and alcohol and acid production. The beverage obtained showed high yield (about $60 \%$ ), ideal alcoholic content $(12.1 \%, \mathrm{v} / \mathrm{v})$, characteristic color of the fruit, clearness, pleasant flavor and high acceptability $(81.9 \%)$. The fermentation process without enzymatic hydrolysis of pejibaye starch and increased beverage volume did not affect the good quality and acceptability of the pejibaye beverage. The increased water:pulp ratio of the mash formulation contributed to the high beverage yield.

Keywords: pejibaye fruit; fermentation; Saccharomyces cerevisiae; beverage; chemical composition; sensory evaluation.

\section{1 - INTRODUÇÃO}

O cultivo da pupunheira (Bactris gasipaes Kunth) é realizado em toda Amazônia. O pico da safra coincide com a estação chuvosa e os frutos, em cachos, são comercializados em feiras na forma in natura. Pesquisas mostram diferenças na concentração da maioria dos constituintes químicos do fruto [2], porém, para os consumidores, apenas a de lipidios e carboidratos influem na preferência e delimitam a finalidade de uso. A população da Amazônia conserva e/ou utiliza os frutos de diversas formas, tais como: desidratação (farinha), apertização (juntamente com xarope de açúcar ou salmoura), fritura (como tira-gosto para acompanhar bebidas) e cocção (com ou sem adição de sal). A conservação e processamento ainda são realizados de forma artesa${ }^{1}$ Recebido para publicação em 13/06/2001. Aceito para publicação em 22/02/2202 (000675).

${ }^{2}$ Instituto Nacional de Pesquisas da Amazônia - INPA, Caixa Postal 478, CEP 69083-000 - AM, BR

* A quem a correspondência deve ser enviada nal e em escala doméstica; porém, quantidades maiores são processadas em algumas regiões produtoras, destacando-se as do projeto "Reca" (Reflorestamento Econômico Consorciado e Adensado) e "Aspruve" (Associação dos Produtores Rurais Vencedora) em Rondônia.

$\mathrm{Na}$ região, o potencial econômico dos frutos da pupunheira decorre da grande aceitação e diversas formas de consumo [10], alta qualidade alimentícia em função de seu valor energético e pró-vitamínico [21] e alta produtividade agricola [1].

A característica amilácea da pupunha indica sua utilização para produção de farinhas [1, 5, 14] e de bebidas alcoólicas [15, 16, 17, 19]. Bebidas alcoólicas fermentadas são produzidas e consumidas, geralmente, em ocasiões comemorativas, por indigenas da Amazônia e dos Andes. Dependendo da região e da etnia, há variações nas matérias-primas e no tempo de fermentação, porém, a hidrólise do amido pela incorporação da ptialina salivar, durante a mastigação prévia da matéria-prima é 
um procedimento comum. As denominações de "caiçuma" e "chicha" são empregadas, respectivamente, para as bebidas fermentadas de pupunha na Amazônia [10] e de milho, mandioca ou outras fontes amiláceas nos Andes [4].

Bebidas alcoólicas fermentadas foram obtidas no Instituto Nacional de Pesquisas da Amazônia - INPA. SOTERO, GARCIA \& LESSI [19] por fermentação espontânea obteve a "caiçuma", uma bebida turva, contendo 33\% de polpa residual e teor alcoólico de 1,5\% (v/v). Após 25 dias de fermentação do mosto de camucamu, corrigido com adição de sacarose e Saccharomyces cerevisiae como agente da fermentação, MAEDA [11] obteve uma bebida limpida, de sabor e aroma agradáveis, teor alcoólico de $11,5 \%(\mathrm{v} / \mathrm{v})$ e com aproximadamente $50 \mathrm{mg} \%$ de ácido ascórbico residual. PANTOJA DE OLIVEIRA [15] por fermentação semi-sólida induzida por Saccharomyces cerevisiae obteve duas bebidas a partir de pupunha. Para a elaboração das bebidas, o amido foi previamente hidrolisado. Na primeira, a hidrólise foi feita pela adição de alfa e glicoamilase comercial (NOVO Nordisk S/A) e na segunda, pelo inóculo de Aspergillus awamori, produtor de alfa e glicoamilase. As bebidas apresentaram aspecto limpido, sabor e aroma agradáveis, coloração variando de amarelo-ouro a amareloalaranjado e teor alcoólico de 10 a $12 \%$ (v/v).

As pesquisas mostram que a partir da polpa de pupunha obtém-se bebida alcoólica fermentada com limpidez, graduação alcoólica, coloração, sabor e aroma desejáveis. O presente trabalho teve por objetivo, aumentar o rendimento em bebida a partir da polpa de pupunha e facilitar o processo pela exclusão da etapa de hidrólise do amido e aumento do volume de água no mosto.

\section{2 - MATERIAL E MÉTODOS}

\section{1 - Preparo e avaliação da matéria-prima}

O trabalho foi realizado no Departamento de Tecnologia de Alimentos do INPA. Os cachos de pupunha da raça Solimões foram adquiridos nos entrepostos de comercialização de frutos regionais na região portuária de Manaus. Os frutos foram despencados, selecionados quanto à sanidade e maturação, lavados e avaliados quanto ao rendimento em polpa. Dos frutos foram separadas duas amostras para a determinação da composição química, sendo uma submetida ao cozimento (1 Kg de fruto e água suficiente para cobri-los) em temperatura de $\pm 100^{\circ} \mathrm{C}$ por duas horas e meia. O restante dos frutos foi submetido ao branqueamento $\left( \pm 140^{\circ} \mathrm{C}\right)$ por 5 minutos em tacho de aço inoxidável (capacidade de 100 litros e aquecimento a vapor) e após o resfriamento foram acondicionados em sacos de polietileno de alta densidade e estocados $\left(-10^{\circ} \mathrm{C}\right)$ para uso posterior na elaboração da bebida.

Para a caracterização química foram realizadas (em triplicata) as determinações de umidade $\left(65^{\circ} \mathrm{C}\right.$ em estufa com circulação forçada de ar), cinzas (incineração em mufla a $550^{\circ} \mathrm{C}$ ), fibra total [9], lipídios (extração com éter de petróleo em Soxhlet), carotenóides totais [8] e proteinas solúveis pelo método de Biureto [7]; os açúcares e amido após a hidrólise ácida [18] foram quantificados pelo método de Somogy-Nelson [20].

\section{2 - Processo fermentativo}

Para o preparo do mosto os frutos foram descongelados, cozidos por duas horas e trinta minutos à temperatura de $\pm 100^{\circ} \mathrm{C}$, despolpados e triturados. Porções (em triplicata) de um quilograma foram esterilizadas (autoclave a $120^{\circ} \mathrm{C}$ por 15 minutos), adicionadas de quatro litros de xarope de sacarose (com concentração suficiente para se obter $12 \%$ de álcool) e inoculadas com a levedura $S$. cerevisiae (seca ativa) na concentração de $1 \%$.

O processo fermentativo foi conduzido por sete dias em temperatura de $27 \pm 1^{\circ} \mathrm{C}$ e monitorado (em triplicata) a cada 24 horas quanto a umidade $\left(65^{\circ} \mathrm{C}\right.$ em estufa com circulação forçada de ar), pH (pHmetro), acidez total titulável (titulação com $\mathrm{NaOH} 0,01 \mathrm{~N}$ ), sólidos solúveis totais (refratômetro), produção de álcool [9], carotenóides totais [8], amido [18] e açúcares redutores quantificados pelo método de Somogy-Nelson [20]. A eficiência fermentativa, rendimento e produtividade em etanol foram calculados [15].

\section{3 - Obtenção e avaliação da bebida}

Após decantação, filtração em algodão e acondicionamento em garrafas de vidro (capacidade de um litro) a fermentação foi interrompida por pasteurização $\left(85^{\circ} \mathrm{C}\right.$ por seis minutos) seguida de resfriamento (banho de água com gelo) e estocagem a $5^{\circ} \mathrm{C}$. Após 30 dias a bebida foi avaliada quanto ao $\mathrm{pH}$ (pHmetro), acidez total titulável (titulação com $\mathrm{NaOH} 0,01 \mathrm{~N}$ ), açúcares redutores pelo método de Somogy-Nelson [20], sólidos solúveis totais (refratometria), grau alcoólico [9] e carotenóides totais [8].

A bebida alcoólica fermentada de pupunha foi adicionada de 9\% de açúcar, grau de edulcoração recomendado por PANTOJA DE OLIVEIRA [15] e analisada sensorialmente por 35 pessoas não treinadas, quanto a aceitabilidade por meio de escala hedônica estruturada de sete pontos [12].

\section{4 - Análise dos dados}

Os resultados foram analisados estatisticamente, aplicando-se análise de variância e teste de Tukey para comparação múltipla de média, com nivel de significância de $5 \%$.

\section{3 - RESULTADOS E DISCUSSÃO}

\section{1 - Características da pupunha}

Para caracterizar a matéria-prima utilizada para o preparo da bebida foram realizadas análises na polpa do fruto in natura e cozido, cujos resultados são apresentados na Tabela 1. 
Como grande quantidade de lipídios é indesejável na elaboração de "caiçuma", os índios cortam a base e ápice dos frutos antes da cocção para facilitar sua liberação e posterior remoção juntamente com a água de cozimento. Seguindo a tradição indigena, neste estudo, esse procedimento foi adotado. Parte do amido (positivo no teste qualitativo com iodo) e dos lipídios agregados de pigmentos (detecção visual) foi carreada para a água e descartados no processo de drenagem após o cozimento dos frutos.

A solubilização e hidrólise destacam-se como fatores que influenciaram no perfil dos componentes químicos durante a cocção da pupunha. Os resultados da composição química estão expressos em matéria úmida, porém, quando em base seca, mostram que a remoção de parte dos lipídios e amido ocasionou a concentração de proteínas, fibras e açúcares. Em base úmida, observa-se a diluição de alguns componentes ocasionada pela absorção de água.

O decréscimo do amido (Tabela 1) indica a ação do aquecimento na hidrólise parcial, cuja glicose liberada foi eliminada no processo de lavagens sucessivas durante seu doseamento. Essa hidrólise é reforçada pela detecção de maiores quantidades de açúcares redutores na polpa cozida. A concentração de amido de 44,32 e $35,69 \mathrm{~g} / 100 \mathrm{~g}$ na polpa in natura e cozida, respectivamente, decresceu para 17,0g/100g após a autoclavagem.

TABELA 1. Composição química da polpa de pupunha (Bactris gasipaes Kunth) da raça Solimões

\begin{tabular}{lrr}
\hline Constituintes $(*)$ & in natura & \multicolumn{1}{c}{ Cozida } \\
\hline Umidade $(\mathrm{g} / 100 \mathrm{~g})$ & $46,0 \pm 0,42$ & $54,63 \pm 0,28$ \\
Proteínas $(\mathrm{g} / 100 \mathrm{~g})$ & $1,30 \pm 0,09$ & $1,16 \pm 0,07$ \\
Lipídios $(\mathrm{g} / 100 \mathrm{~g})$ & $5,93 \pm 0,43$ & $4,52 \pm 0,23$ \\
Amido $(\mathrm{g} / 100 \mathrm{~g})$ & $44,32 \pm 0,32$ & $35,69 \pm 3,20$ \\
Açúcares redutores $(\mathrm{g} / 100 \mathrm{~g})$ & $0,13 \pm 0,05$ & $0,39 \pm 0,03$ \\
Fibra total $(\mathrm{g} / 100 \mathrm{~g})$ & $0,76 \pm 0,12$ & $0,69 \pm 0,20$ \\
Cinza $(\mathrm{g} / 100 \mathrm{~g})$ & $0,72 \pm 0,16$ & $0,50 \pm 0,13$ \\
Carotenóides totais $(\mathrm{mg} / 100 \mathrm{~g})$ & $2,46 \pm 0,31$ & $4,71 \pm 0,40$ \\
\hline
\end{tabular}

(*) Resultados expressos em matéria integral

Em função da irritação na mucosa bucal, provocada pelo fruto in natura, a pupunha só é utilizada (para consumo e preparo de produtos) após a cocção. Além de eliminar a irritabilidade, o cozimento acentua a coloração. Independente de ser amarela ou alaranjada, visualmente observa-se a nítida diferença entre o fruto in natura e o cozido. A intensificação na tonalidade da coloração alaranjada, de clara para escura, é mostrada também, pelos carotenóides totais, cujos valores aumentaram de 2,46 para $4,71 \mathrm{mg} / 100 \mathrm{~g}$, sugerindo mudanças químicas nesses pigmentos [3, 13]. MONTENEGRO \& MARINHO [13] identificaram o $\beta$-caroteno como o carotenóide majoritário e encontraram valores de 30,06 e 34,09 mg/g de amostra no fruto in natura e cozido, respectivamente. Os autores sugerem a ocorrência de descomplexação de carotenóides para o aumento de 13,39\% com o cozimento. Observou-se também, que quando armazenada ao ambiente ou em geladeira, a polpa in natura perde a coloração e a cozida mantém; além disso, o resíduo da extração dos carotenóides da polpa in natura torna-se incolor enquanto que o da cozida mantém a coloração amarela clara, indicativa da presença de pigmentos não extraiveis pelo uso da metodologia adotada.

\section{2 - Processo fermentativo}

O meio de fermentação constituiu-se em uma massa homogênea, de coloração alaranjada, característica da pupunha cozida. Durante o processo fermentativo a coloração, avaliada visualmente, permaneceu inalterada e a massa tornou-se gradativamente liquefeita. Em função da solubilidade e densidade dos componentes do mosto, observou-se a partir de 72 horas de fermentação, a separação de três fases, isto é, a superior constituída por uma fina camada lipídica, a intermediária pela camada aquosa e a inferior formada pelas partículas densas da massa. Esse comportamento levou ao emprego da homogeneização diária no momento da retirada das amostras para as análises. O aumento da umidade a partir de 24 horas de fermentação e a estabilidade dos carotenóides totais em valores em torno de $2,2 \mathrm{mg} / 100 \mathrm{~mL}$ de mosto são mostrados na Figura 1. A liberação de $\mathrm{CO}_{2}$, indicativa do processo fermentativo, foi visualizada pela formação de bolhas no interior da massa, cerca de três horas após o inóculo da levedura.

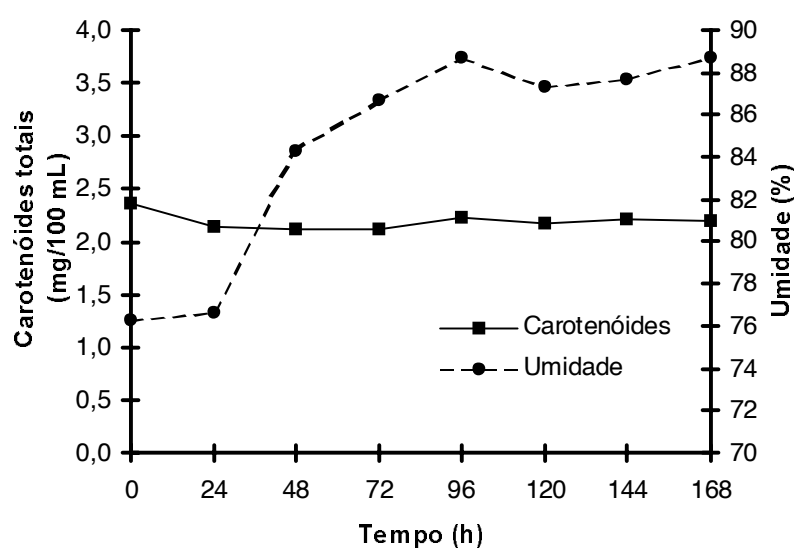

FIGURA 1. Variação de umidade e carotenóides totais em função do tempo de fermentação

O monitoramento diário permitiu observar as mudanças na constituição química do mosto, indicativas do processo fermentativo. Os resultados da acidez total titulável mostram um aumento gradativo na produção de ácidos, ocasionando um decréscimo significativo nos valores de $\mathrm{pH}$, especialmente nas primeiras 24 horas após o inóculo do agente fermentativo (Figura 2). Comportamento semelhante foi observado também por PANTOJA DE OLIVEIRA et al. [17].

O calor empregado no preparo da pupunha para a fermentação, ocasionou hidrólise parcial do amido. Após o cozimento e autoclavagem observou-se redução signi- 
ficativa de 19,47 e 62,77\%, respectivamente. A diferença no teor de amido da polpa autoclavada para o mosto $(4,11 \mathrm{~g} / 100 \mathrm{~mL})$ foi decorrente da diluição pela adição do xarope. A não adição de enzimas amiloliticas e a incapacidade da levedura em utilizar o amido são mostradas pelo comportamento estável desse carboidrato durante o processo fermentativo (Figura 3) e pela produção de álcool dentro da concentração esperada (12\%). Em função dos custos operacionais da hidrólise por $\alpha$-amilase e glicoamilase [15], o remanescente de $4,1 \%$ de amido no mosto não foi utilizado no processo fermentativo.

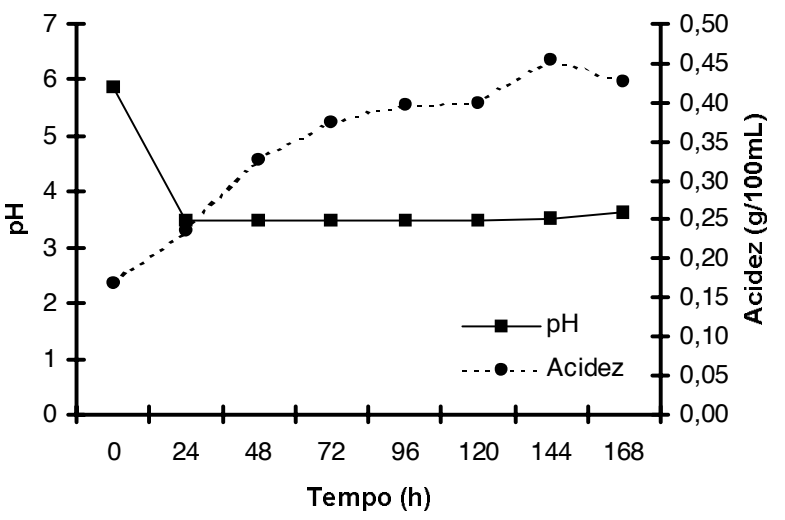

FIGURA 2. Variação de pH e acidez em função do tempo de fermentação

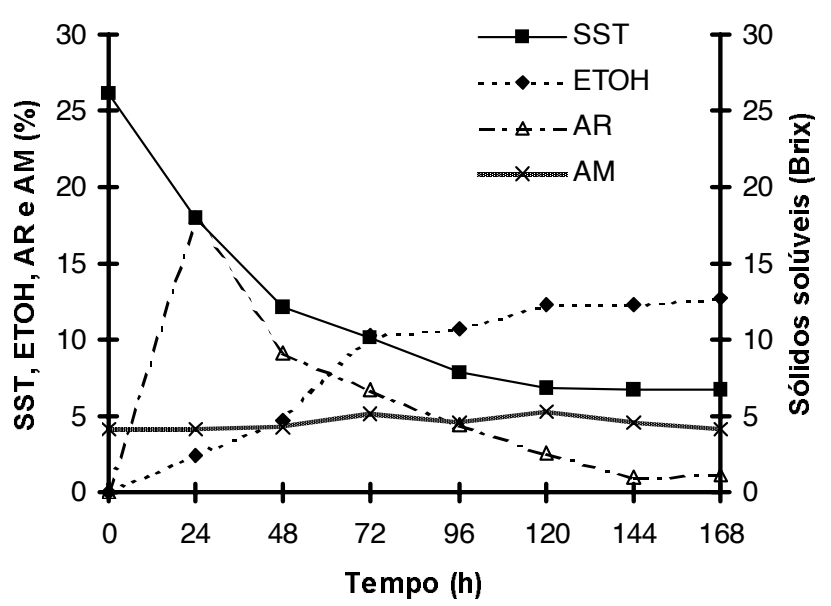

FIGURA 3. Variação dos teores de amido (AM), sólidos solúveis totais (SST), cinética do consumo de açúcares (AR) e produção de álcool (ETHO) em função do tempo de fermentação

A baixa concentração de substrato na polpa cozida foi corrigida pela adição sacarose, a qual, por ação invertásica da levedura, originou aumento significativo dos açúcares redutores nas primeiras 24 horas de fermentação. Os açúcares, compondo a maioria dos sólidos solúveis totais, foram consumidos rapidamente nas primeiras 48 horas e a quase totalidade de etanol foi produzida nas primeiras 72 horas. O consumo de açúcares e a produção de etanol ocorreram de forma inversamente proporcional com correlação negativa de 0,95. No processo fermentativo os valores de $0,50 \mathrm{gP} / \mathrm{gS}$ para o rendimento de substrato convertido em álcool e
98,35\% para a eficiência fermentativa são considerados bons e semelhantes aos obtidos por PANTOJA DE OLIVEIRA [15] e PANTOJA DE OLIVEIRA et al. [17]. A máxima produtividade em etanol foi atingida com 72 horas de fermentação, com valor de 1,13gP/L.h. Os resultados da comparação entre as médias, pelo teste de Tukey, estão apresentados na Tabela 2.

TABELA 2. Resultados do teste de Tukey para comparação de médias das determinações analíticas realizadas durante o processo fermentativo.

\begin{tabular}{lccccccccc}
\hline \multicolumn{1}{c}{ Componentes } & \multicolumn{8}{c}{ Tempo de fermentação (horas) } \\
\cline { 2 - 10 } & 0 & 24 & 48 & 72 & 96 & 120 & 144 & 168 \\
Umidade (\%) & $76,31 \mathrm{c}$ & $76,61 \mathrm{c}$ & $84,31 \mathrm{~b}$ & $86,66 \mathrm{ab}$ & $88,74 \mathrm{a}$ & $87,35 \mathrm{a}$ & $87,73 \mathrm{a}$ & $88,68 \mathrm{a}$ \\
$\mathrm{pH}$ & $5,86 \mathrm{a}$ & $3,48 \mathrm{c}$ & $3,47 \mathrm{c}$ & $3,48 \mathrm{c}$ & $3 \mathrm{c} 47 \mathrm{c}$ & $3,50 \mathrm{c}$ & $3,51 \mathrm{c}$ & $3,62 \mathrm{~b}$ \\
Acidez (\%) & $0,17 \mathrm{f}$ & $0,23 \mathrm{e}$ & $0,33 \mathrm{~d}$ & $0,37 \mathrm{c}$ & $0,40 \mathrm{bc}$ & $0,31 \mathrm{~d}$ & $0,45 \mathrm{a}$ & $0,43 \mathrm{ab}$ \\
Amido (\%) & $4,11 \mathrm{a}$ & $4,21 \mathrm{a}$ & $4,33 \mathrm{a}$ & $5,11 \mathrm{a}$ & $4,59 \mathrm{a}$ & $5,33 \mathrm{a}$ & $4,53 \mathrm{a}$ & $4,12 \mathrm{a}$ \\
Açúcares (\%) & $0,030 \mathrm{f}$ & $18,02 \mathrm{a}$ & $9,11 \mathrm{~b}$ & $6,73 \mathrm{c}$ & $4,41 \mathrm{~d}$ & $2,52 \mathrm{de}$ & $0,96 \mathrm{ef}$ & $1,07 \mathrm{ef}$ \\
Sólidos solúveis ( $\left.{ }^{\circ} \mathrm{Brix}\right)$ & $26,16 \mathrm{a}$ & $18,00 \mathrm{~b}$ & $12,16 \mathrm{c}$ & $10,16 \mathrm{~cd}$ & $7,83 \mathrm{de}$ & $6,83 \mathrm{e}$ & $6,66 \mathrm{e}$ & $6,66 \mathrm{e}$ \\
Carotenóides (mg/100g) & $2,35 \mathrm{a}$ & $2,13 \mathrm{a}$ & $2,12 \mathrm{a}$ & $2,11 \mathrm{a}$ & $2,22 \mathrm{a}$ & $2,17 \mathrm{a}$ & $2,21 \mathrm{a}$ & $2,18 \mathrm{a}$ \\
Álcool (\%) & $0,00 \mathrm{e}$ & $2,46 \mathrm{~d}$ & $4,73 \mathrm{c}$ & $10,32 \mathrm{~b}$ & $10,74 \mathrm{ab}$ & $12,32 \mathrm{ab}$ & $12,26 \mathrm{ab}$ & $12,74 \mathrm{a}$
\end{tabular}

Letras iguais nas linhas representam resultados não significativos e letras diferentes representam resultados com diferença significativa.

\section{3 - Aspectos químicos e organolépticos da bebida}

A bebida fermentada de pupunha apresentou sabor e aroma agradáveis. A coloração alaranjada caracteristica do fruto cozido foi mantida na bebida, porém, com tonalidade mais clara. O aspecto limpido da bebida é decorrente dos cuidados com a etapa de clarificação, tais como, sedimentação, trasfega e filtragem.

A composição química da bebida, sem adição de açúcar é mostrada na Tabela 3. O teor residual de açúcares redutores e a graduação alcoólica de $95,2 \mathrm{~g} / \mathrm{L}$ da bebida assemelham-se às caracteristicas de vinho seco de mesa [6]. A bebida apresentou valores de acidez total titulável, açúcares, álcool e sólidos solúveis totais, superiores às bebidas obtidas por PANTOJA DE OLIVEIRA et al. [17] que foram de 4,2; 0, 16 e 75, $1 \mathrm{~g} / \mathrm{L}$ e $6,4^{\circ} \mathrm{Brix}$, respectivamente. Os carotenóides totais [5] e pró-vitamínicos [21], responsáveis, em parte, pela coloração alaranjada do fruto, foram quase que totalmente removidos, juntamente com os lipídios, nas etapas de cozimento e filtração.

TABELA 3. Resultados das analises físico-químicas das bebidas e desvio padrão

\begin{tabular}{ll} 
Constituintes & Média DP \\
\hline $\mathrm{pH}$ & $3,88 \pm 0,03$ \\
Acidez total $(*)$ & $6,40 \pm 0,04$ \\
Açúcares redutores $(\mathrm{g} / \mathrm{L})$ & $1,01 \pm 0,06$ \\
Sólidos solúveis $\left({ }^{\circ}\right.$ Brix $)$ & $7,25 \pm 0,35$ \\
Álcool $(\mathrm{g} / \mathrm{L})$ & $95,2 \pm 0,07$ \\
Carotenóides totais $(\mu \mathrm{g} / \mathrm{L})$ & $7,0 \pm 0,00$
\end{tabular}

(*) Acidez em solução normal por cento (v/v)

A bebida apresentou bom nivel de aceitabilidade $(81,9 \%)$, sendo que $3,12 \%$ dos provadores foram indiferentes; $21,87 \%$ gostaram ligeiramente; $46,87 \%$ gosta- 
ram e $28,12 \%$ gostaram muito. Nenhum provador marcaou os itens desgostei muito, desgostei e desgostei ligeiramente. O valor de aceitabilidade obtido foi superior aos das bebidas alcoólicas de pupunha (65 a $76 \%)$ produzidas por PANTOJA DE OLIVEIRA [15].

$\mathrm{O}$ aumento da relação água:polpa aumentou o rendimento em bebida para aproximadamente $60 \%$, o qual pode ser considerado satisfatório quando comparado com o de $25 \%$ obtido em estudos anteriores, nos quais a proporção água:polpa foi menor. Comparado com essas bebidas, o aumento do volume de água no mosto não interferiu de forma negativa na coloração, sabor, aroma e aceitabilidade da bebida.

\section{4 - CONCLUSÕES}

O aumento da proporção água:polpa no mosto contribuiu para o rendimento da bebida. A exclusão da etapa de hidrólise enzimática e o aumento do rendimento não interferiram na graduação alcoólica, coloração, sabor, aroma e aceitabilidade da bebida alcoólica fermentada de pupunha.

\section{5 - REFERÊNCIAS BIBLIOGRÁFICAS}

[1] CLEMEnT, C.R. Pupunha uma árvore domesticada. Ciência Hoje, v. 5, n. 29, 1987.

[2] CLEMENT, C.R.; ARKCOLL, D.B. The Bactris gasipaes H. B. K. (Palmae) as an oil producing crop: potential and priorities of investigation. In. Informe del Seminario - Taller sobre Oleaginosas Promisorias. L. E. Forero P. 1985. (Ed). Bogotá (Colombia): Programa Interciencias de Recursos Biologicos (Spanish).

[3] BIANCHINI, R.; PENTEADO, M.de V.C. Carotenóides de pimentões amarelos (Capsicum annuum, L.). Caracterização e verificação de mudanças com o cozimento. Campinas-SP. Ciênc. Tecnol. Aliment., v. 18, n. 3 , p. 283-288, 1998.

[4] DEMiATE, I.M.; OETTERER, M.; WOSIACKI, G. A fermentação como processo de enriquecimento nutricional. Bol. SBCTA., v. 28, n. 2, p. 170-181, 1994.

[5] GOIA, C.H. Processamento, caracterização e estabilidade da farinha de pupunha (Bactris gasipaes H.B.K.). 1992, 90 p. Dissertação de Mestrado. Faculdade de Ciências da Saúde, Universidade do Amazonas.

[6] GUTIERREZ, L.E. 1999. Rumo à biotecnologia de alimentos e bebida. <http://www.esalq.usp.br/dcta/ biotec/biotec3.htm>.

[7] HARRIS, E.L.V.; ANGAL, S. Protein purification methods. Oxford, England. Ed. IRL PRESS, 6 a ed., 1994, 317 p.

[8] HIGBY, W.K. A simplified method for determination of some aspects of the carotenoid distribution in natural and carotene - fortified orange juice. Journal Food Science, Chicago. v. 27, n. 1, p. 42-49, 1962.

[9] INSTITUTO ADOLFO LUTZ. Normas Analíticas Métodos químicos e físicos para análise de alimentos. São Paulo-SP, v. 1, $3^{\text {a }}$ ed. São Paulo. 1985, 317p.

[10] KERR, L.; CLEMENT, C.R.; KERR, W.E. Cozinhando com a pupunha. Manaus-INPA, 19 a ed., 1997, 95 p.

[11] MAEDA, R.N. Adequação tecnológica do camu-camu (Myrciaria dubia Mc Vaugh) para produção de vinho. 1999, 58 p. Monografia, Faculdade de Ciências Agrárias, Universidade do Amazonas.

[12] MONTEIRO, C.L.B. Técnicas de avaliação sensorial. Curitiba-PR, CEPPA, 2a . ed., 1984, $101 \mathrm{p}$.

[13] MONTENEGRO, M.F.; MARINHO, H.A. Estudos de carotenóides e pro-vitamina A no fruto e farinha de pupunha (Bactris gasipaes H.B.K.). Anais da XI Jornada de Iniciação científica do INPA. Manaus-AM, p. 112-113, 2002.

[14] OLIVEIRA, M.K.S.Características Físico-químicas, viscoamilográficas e farinográficas de farinha de pupunha (Bactris gasipaes Kunth) e sua avaliação tecnológica como farinha mista na elaboração de massas alimentícias. 1999, 119 p. Dissertação de Mestrado. Faculdade de Ciências da Saúde, Universidade do Amazonas.

[15] PANTOJA DE OLIVEIRA, L. Produção de bebida alcoólica a partir de pupunha (Bactris gasipaes Kunth) por fermentação dirigida. 2000, 160 p. Dissertação de Mestrado. Faculdade de Ciências da Saúde, Universidade do Amazonas.

[16] PANTOJA DE OLIVEIRA, L.; MAEDA, R.N.; ANDRADE, J.S.; PEREIRA Jr., N.; CARVALHO, S.M.S.; ASTOLFIFILHO, S. Bebida alcoólica fermentada a partir de pupunha (Bactris gasipaes Kunth). Anais do XVII Congresso Brasileiro de Ciência e Tecnologia de Alimentos. Fortaleza-CE, 2000, p. 9.99.

[17] PANTOJA DE OLIVEIRA, L.; MAEDA, R.N.; ANDRADE, J.S.; PEREIRA Jr., N.; CARVALHO, S.M.S.; ASTOLFIFILHO, S. Processo fermentativo para produção de bebida alcoólica de pupunha (Bactris gasipaes Kunth). Biotecnologia Ciência \& Desenvolvimento. v. 3 , n. 19, p. 50-54, 2001.

[18] RANGANNA, S. Handbook of analysis and quality control for fruit and vegetable products. 1986, p. 27-30.

[19] SOTERO, V.E.; GARCIA, D.; LESSI, E. Bebida fermentada a partir de pujuayo (Bactris gasipaes H.B.K.) parametros y evolucion. Iquitos-Peru. Folia Amazônica. v. 8, n. 1, p. 5-18, 1996.

[20] SOUTHGATE, D.A.T. Determination of food carbohydrates. London. Ed. Applied Science Publishers LTD. 1976, 177 p.

[21] YUYAMA, L.K.O.; FÁVARO, R.M.; YUYAMA, K.; VANNUCCHI, H. Bioavaliability of vitamin A from peach palm (Bactris gasipaes H.B.K.) and from mango (Mangifera indica L.) in rates. Nutrition Research, USA., v. 11, p. 1167-1175, 1991. 